\title{
Unconscious Psychological Treatments for Physiological Survival Circuits
}

\author{
Vincent Taschereau-Dumouchel ${ }^{1,2,{ }^{*}, \text { Ka-yuet Liu }}{ }^{3,4}$, and Hakwan Lau ${ }^{1,2,5,6,{ }^{*}}$ \\ ${ }^{1}$ Department of Psychology, UCLA, Los Angeles, 90095, USA. \\ ${ }^{2}$ Department of Decoded Neurofeedback, ATR Computational Neuroscience Laboratories, Kyoto, \\ 619-0288, Japan. \\ ${ }^{3}$ Departments of Sociology, UCLA, Los Angeles, 90095, USA. \\ ${ }^{4}$ California Center for Population Research, UCLA, Los Angeles, 90095, USA. \\ ${ }^{5}$ Brain Research Institute, UCLA, Los Angeles, 90095, USA. \\ ${ }^{6}$ Department of Psychology, University of Hong Kong, Pokfulam Road, Hong Kong.
}

\begin{abstract}
The idea of targeting unconscious or implicit processes in psychological treatments is not new, but until recently it has not been easy to manipulate these processes without also engaging consciousness. Here we review how this is possible, using various modern cognitive neuroscience methods including a technique known as Decoded Neural-Reinforcement. We discuss the general advantages of this approach, such as how it can facilitate double-blind placebo-controlled studies, and minimize premature patient dropouts in the treatment of fear. We also speculate how this may generalize to other similar physiological survival processes.
\end{abstract}

\section{Keywords}

Unconscious interventions; Neural-Reinforcement; Fear; Survival/defensive circuit

\section{Introduction}

Conscious emotions are generated by complex networks in the nervous system [1,2]. Some of the key structures in this network, like the amygdala, influence behavior and physiological responses important for survival [2]. According to one influential framework known as the higher-order view, much of these brain processes are unconscious, unless they are monitored or meta-represented by some higher-order processes [1,3,4]. Although still debated, this higher-order perspective has gradually gained some empirical traction. Our

Correspondence should be addressed to: Vincent Taschereau-Dumouchel (vincenttd@ucla.edu) \& Hakwan Lau (hakwan@ gmail.com), 1285 Franz Hall Box 951563, Los Angeles, CA 90095.

Publisher's Disclaimer: This is a PDF file of an unedited manuscript that has been accepted for publication. As a service to our customers we are providing this early version of the manuscript. The manuscript will undergo copyediting, typesetting, and review of the resulting proof before it is published in its final citable form. Please note that during the production process errors may be discovered which could affect the content, and all legal disclaimers that apply to the journal pertain. 
goal here is to discuss its various clinical implications. We will use fear as an example, to focus on how the principles of psychotherapy may be applied to the unconscious physiological components underlying fear processing. We end by speculating how these perspectives may generalize to other survival-related physiological circuits.

\section{Targeting the unconscious: why would it work?}

Humans evolved in a complex environment where the timely production of defensive responses could often be a matter of life and death. As a result, fixed and rapid survival reactions such as fighting, fleeing or freezing are response strategies that greatly favored survival $[5,6]$. While seemingly simplistic, these behaviors involve complex neuronal networks for the detection of threats and for the production of appropriate defensive reactions. Some of these behaviors have been suggested to occur automatically $[5,6]$ without requiring the conscious awareness of the relevant threat.

Various methods have been employed to dissociate between conscious and unconscious processes in the brain [4,7]. Specifically, in the case of fear [9], unconscious stimulus presentations have been shown to increase physiological reactivity [8-15] and to affect behavioral outcomes [16-19] (but see [14,20]). Functional magnetic resonance imaging (fMRI) studies have shown that the amygdala, a central structure in the survival/defensive circuit [2], is one of the key regions activated during unconscious fear perception (for a review, see [21]). Importantly, these findings indicate that, without consciousness, some critical regions associated with fear may not be implicated. These include higher-order regions such as the prefrontal cortex (ventromedial [vmPFC], dorsolateral [dlPFC], dorsomedial [ $\mathrm{dmPFC}]$, and orbitofrontal), the anterior cingulate cortex, and the insula (although, see [22-24]). These regions were associated with conscious fear perception as they are notably involved in the successful treatment of specific phobia [25-27], panic disorder [28-30], generalized anxiety disorder [31], obsessive-compulsive disorder [32,33], post-traumatic stress disorder (PTSD) [34,35], and social anxiety [35,36]. This dissociation between conscious and unconscious processing is in line with the previous literature indicating the importance of prefrontal regions for consciousness $[4,7,37]$.

The dissociation between conscious and unconscious processes raises the question of how these two brain networks may interact. Is the conscious feeling of fear a late stage 'read-out' of the activity of the survival/defensive circuit, or is it part of an independent, parallel process? Although theoretical models are still debated (e.g., [1,38]), in general it seems plausible that the conscious experience of fear isn't completely independent from or totally unrelated to the unconscious physiological process (see figure 1). In particular, under the higher-order view of consciousness [4], we expect the experience of fear to be different from its physiological basis, but the former should meaningfully reflect the latter in most cases. As such, a clinical intervention designed to target the unconscious survival/defensive circuits alone (see table 1) may ultimately alleviate symptoms at the conscious level.

Curr Opin Behav Sci. Author manuscript; available in PMC 2019 December 01. 


\section{Advantages of targeting the unconscious}

An 'unconscious' clinical or therapeutic procedure can refer to: (1) an intervention targeting an unconscious process, or (2) an intervention carried without the patient (and sometime the therapist) being aware of the purpose or content of the treatment. The first idea has been prominent within psychoanalytic traditions: Sigmund Freud is probably best known for popularizing the idea of targeting the unconscious mind. This approach is still at the core of modern psychodynamic treatments [46,47] and unconscious or implicit processes are also involved in most modern psychotherapeutic approaches [48]. Other methods, such as hypnosis [49], eye movement desensitization reprogramming [50], transcranial magnetic stimulation [51], and transcranial direct current stimulation [52] have also been used to change implicit processes in the brain. Our focus here, however, is on the advantages of novel treatments that meet both criteria of unconsciousness.

One major advantage for this kind of fully unconscious interventions (i.e., satisfying both criteria (1) and (2) above) is that they can be demonstrated in double-blind placebocontrolled experiments, i.e., where neither the therapists nor the patients are aware of the nature of the intervention [53,54]. Traditionally, this is difficult to achieve, because the nature of many psychotherapeutic treatments cannot be completely hidden from the therapists carrying the intervention. Although many arguments have been made as to why double-blind controls may not be totally necessary under all circumstances [55], the advantages of doing so - when it is possible - are obvious. It allows for rigorous experimentation, which can further integrate psychological treatments with modern medicine. Considering the origins of unconscious treatments, where criticisms that it was unscientific [56] have led to serious repercussions, this point should not be underappreciated. More generally, the placebo effect is known to be complex and large under many circumstances [57] and not controlling for it casts legitimate doubts to a treatment effectiveness.

To achieve this kind of intervention outside of awareness, we have recently made use of a new method called Decoded Neural-Reinforcement (also called Decoded Neurofeedback, DecNef) [58], in which participants' brain patterns representing specific content (e.g. visual objects) are paired with reward [58]. Importantly, it has been shown that subjects were generally unaware of the contents of these induced brain activity, as well as the general purposes of the procedure, when they were not explicitly instructed about them [58,59].

We have capitalized on the unconscious nature of this intervention method to overcome one challenge traditionally faced by exposure therapy for common fears. In conventional exposure therapy, patients have to consciously face their fear which is subjectively aversive and high rates of premature attrition have been reported [60]. Also, conscious exposure can lead patients to rely on conscious "safety signals", which have been shown to interfere with the effectiveness of the procedure [61]. By using decoded Neural-Reinforcement, we bypassed these issues, by directly rewarding the spontaneous occurences of the relevant brain representations, to make their valence less negative via associative learning $[62,63]$ (Figure 2). 
This approach may open up possibilities of how much we can do 'under the (conscious) hood'. With advancements in brain decoding [64], it is conceivable that unconscious representations beside those for simple objects could eventually be targeted too.

Alternatively, one interesting approach not based on decoded neuroimaging information is to carry unconscious interventions during sleep. Experiments conducted both in animals [65] and in humans $[65,66]$ indicate that memories can indeed be changed by presenting stimuli during slow-wave sleep. Such a procedure has notably been used to achieve olfactory aversive conditioning, to reduce cigarette smoking behavior [67].

\section{Beyond fear?}

These proof-of-concept examples (Figure 2) show that an unconscious physiological target may be malleable and subject to the basic psychological principles of Pavlovian (associative) conditioning [2]. If these associative learning mechanisms apply to the unconscious physiological survival circuitry for fear [1], would this apply to other 'fear-like' unconscious physiological mechanisms too? To what extent are other survival-related physiological mechanisms 'fear-like', where the proposed approach may apply?

Here, we speculate that this issue may have been traditionally unappreciated. Take the immune system for example. Conceptually it shares many features of fear: it detects external 'threats' and reacts in a way that is largely effective, but occasionally it overreacts, leading to the paralysis of the entire system, or blockage of other complementary mechanisms, such as in the case of inflammation. Given the supposed 'physiological' nature of these mechanisms, we might have been initially reluctant to think of them in Pavlovian terms. But it has been shown that even plants are capable of basic Pavlovian learning [68]. Ultimately, many circuits in the nervous system as well as in other parts of our bodies might have been 'designed' under the same principles; all organisms and their evolutionarily older subparts are subjected to similar survival pressure.

Take the immune system for example. It has been reported that it can be conditioned through learning [69]. Placebo effects may happen through such mechanisms as conditioning of the immune system with stimuli or taste of medicine that isn't otherwise effective [70,71]. As mentioned above, the prevalence of placebo effects is often under-appreciated. To what extent can we apply Pavlovian associative learning models to formulate treatments of immune dysfunction?

Of course, there are also clear differences between fear and basic survival mechanisms such as the immune system. For instance, some basic survival circuits can operate without the need for a self-other distinction at the level of the organism because they do not have to regulate complex interactions with the environment. This is in line with the danger model [72], according to which the immune system do not distinguish between self and nonself, but rather mainly focuses on the differences between safety and danger. So in a sense, we should not expect the immune system to be psychologically as complex as some other brain processes.

Curr Opin Behav Sci. Author manuscript; available in PMC 2019 December 01. 
However, recent research has also increasingly highlighted the two-way communications between brain processes with other physiological mechanisms in the body, e.g. the brain-gut connections [71]. It is known that these physiological processes, similar to the hormonal mechanisms related to fear, are bidirectionally connected to processes within the central nervous system. So even if the physiological circuits in question themselves aren't exactly psychological in nature, the above argument may still hold that we may be able to apply psychological principles in manipulating them, via brain processes.

To really test the degree to which these physiological mechanisms can be understood in Pavlovian terms, we can evaluate some counter-intuitive predictions. For example, it is known that fear can spread socially via vicarious learning [73]. If autoimmune responses are to be conceptualized as akin to fear, does it mean they may spread through the social network too? While this may seem surprising, the current empirical data is not entirely incompatible with such possibility (Box 1). Future work may be able to explore this contentious hypothesis further.

To conclude, we draw attention to the implications of some of the most powerful and bestunderstood principles about psychology - namely, Pavlovian conditioning, and explored how they may be applicable to various diseases. By isolating them from consciousness, we hope to show that they are not 'unscientific', as if they were just 'all in our heads'. Instead, they can be demonstrated with experimentally rigorous methods, just like other phenomena in physiological medicine. Importantly, these principles may also have the potential of generalizing beyond processes traditionally thought to be 'psychological'.

\section{Acknowledgments}

This work was supported by the US National Institute of Neurological Disorders and Stroke of the National Institutes of Health (grant no. R01NS088628 to H.L.). V.T-D. is supported by a fellowship from the Fond de Recherche du Québec - Santé (FRQS). K.Y.L. is supported by California Center for Population Research at UCLA (NICHD grant no. P2C HD041022).

\section{References}

1. LeDoux JE, Pine DS. Using Neuroscience to Help Understand Fear and Anxiety: A Two-System Framework. Am J Psychiatry. 2016; 173:1083-1093. ** This manuscript presents the two-system model describing how conscious and unconscious brain processes could interact to generate conscious emotional experiences. [PubMed: 27609244]

2. Janak PH, Tye KM. From circuits to behaviour in the amygdala. Nature. 2015; 517:284-292. [PubMed: 25592533]

3. LeDoux JE. Semantics, Surplus Meaning, and the Science of Fear. Trends Cogn Sci. 2017; 21:303306. [PubMed: 28318937]

4. Lau H, Rosenthal D. Empirical support for higher-order theories of conscious awareness. Trends Cogn Sci. 2011; 15:365-373. [PubMed: 21737339]

5. LeDoux J, Daw ND. Surviving threats: neural circuit and computational implications of a new taxonomy of defensive behaviour. Nat Rev Neurosci. 2018; doi: 10.1038/nrn.2018.22

6. Mobbs D, Hagan CC, Dalgleish T, Silston B, Prévost C. The ecology of human fear: survival optimization and the nervous system. Front Neurosci. 2015; 9:55. [PubMed: 25852451]

7. Dehaene S, Lau H, Kouider S. What is consciousness, and could machines have it? Science. 2017; 358:486-492. * This article describes the empirical basis of higher-order views of consciousness. [PubMed: 29074769] 
8. Troiani V, Schultz RT. Amygdala, pulvinar, and inferior parietal cortex contribute to early processing of faces without awareness. Front Hum Neurosci. 2013; 7:241. [PubMed: 23761748]

9. Fang Z, Li H, Chen G, Yang J. Unconscious Processing of Negative Animals and Objects: Role of the Amygdala Revealed by fMRI. Front Hum Neurosci. 2016; 10:146. [PubMed: 27092067]

10. Troiani V, Price ET, Schultz RT. Unseen fearful faces promote amygdala guidance of attention. Soc Cogn Affect Neurosci. 2014; 9:133-140. [PubMed: 23051897]

11. Jessen S, Grossmann T. Unconscious discrimination of social cues from eye whites in infants. Proc Natl Acad Sci U S A. 2014; 111:16208-16213. [PubMed: 25349392]

12. Lipp OV, Kempnich C, Jee SH, Arnold DH. Fear conditioning to subliminal fear relevant and non fear relevant stimuli. PLoS One. 2014; 9:e99332. [PubMed: 25198514]

13. Raio CM, Carmel D, Carrasco M, Phelps EA. Nonconscious fear is quickly acquired but swiftly forgotten. Curr Biol. 2012; 22:R477-9. [PubMed: 22720676]

14. Hedger N, Adams WJ, Garner M. Autonomic arousal and attentional orienting to visual threat are predicted by awareness. J Exp Psychol Hum Percept Perform. 2015; 41:798-806. [PubMed: 25867508]

15. Sevenster D, Beckers T, Kindt M. Fear conditioning of SCR but not the startle reflex requires conscious discrimination of threat and safety. Front Behav Neurosci. 2014; 8

16. Gomes N, Silva S, Silva CF, Soares SC. Beware the serpent: the advantage of ecologically-relevant stimuli in accessing visual awareness. Evol Hum Behav. 2017; 38:227-234.

17. Gray KLH, Adams WJ, Hedger N, Newton KE, Garner M. Faces and awareness: Low-level, not emotional factors determine perceptual dominance. Emotion. 2013; 13:537-544. [PubMed: 23398580]

18. Gayet S, Paffen CLE, Belopolsky AV, Theeuwes J, Van der Stigchel S. Visual input signaling threat gains preferential access to awareness in a breaking continuous flash suppression paradigm. Cognition. 2016; 149:77-83. [PubMed: 26807500]

19. Ye X, He S, Hu Y, Yu YQ, Wang K. Interference between conscious and unconscious facial expression information. PLoS One. 2014; 9:e105156. [PubMed: 25162153]

20. Grassini S, Holm SK, Railo H, Koivisto M. Who is afraid of the invisible snake? Subjective visual awareness modulates posterior brain activity for evolutionarily threatening stimuli. Biol Psychol. 2016; 121:53-61. [PubMed: 27760371]

21. Diano M, Celeghin A, Bagnis A, Tamietto M. Amygdala Response to Emotional Stimuli without Awareness: Facts and Interpretations. Front Psychol. 2016; 7:2029. [PubMed: 28119645]

22. Siegel P, Warren R, Wang Z, Yang J, Cohen D, Anderson JF, Murray L, Peterson BS. Less is more: Neural activity during very brief and clearly visible exposure to phobic stimuli. Hum Brain Mapp. 2017; 38:2466-2481. [PubMed: 28165171]

23. Schmack K, Burk J, Haynes J-D, Sterzer P. Predicting Subjective Affective Salience from Cortical Responses to Invisible Object Stimuli. Cereb Cortex. 2016; 26:3453-3460. [PubMed: 26232987]

24. Brooks SJ, Savov V, Allzén E, Benedict C, Fredriksson R, Schiöth HB. Exposure to subliminal arousing stimuli induces robust activation in the amygdala, hippocampus, anterior cingulate, insular cortex and primary visual cortex: a systematic meta-analysis of fMRI studies. Neuroimage. 2012; 59:2962-2973. [PubMed: 22001789]

25. Lipka J, Hoffmann M, Miltner WHR, Straube T. Effects of cognitive-behavioral therapy on brain responses to subliminal and supraliminal threat and their functional significance in specific phobia. Biol Psychiatry. 2014; 76:869-877. [PubMed: 24393393]

26. Nave AM, Tolin DF, Stevens MC. Exposure therapy, D-cycloserine, and functional magnetic resonance imaging in patients with snake phobia: a randomized pilot study. J Clin Psychiatry. 2012; 73:1179-1186. [PubMed: 23059145]

27. Hauner KK, Mineka S, Voss JL, Paller KA. Exposure therapy triggers lasting reorganization of neural fear processing. Proc Natl Acad Sci U S A. 2012; 109:9203-9208. [PubMed: 22623532]

28. Kircher T, Arolt V, Jansen A, Pyka M, Reinhardt I, Kellermann T, Konrad C, Lueken U, Gloster AT, Gerlach AL, et al. Effect of cognitive-behavioral therapy on neural correlates of fear conditioning in panic disorder. Biol Psychiatry. 2013; 73:93-101. [PubMed: 22921454]

Curr Opin Behav Sci. Author manuscript; available in PMC 2019 December 01. 
29. Lueken U, Straube B, Konrad C, Wittchen H-U, Ströhle A, Wittmann A, Pfleiderer B, Uhlmann C, Arolt V, Jansen A, et al. Neural substrates of treatment response to cognitive-behavioral therapy in panic disorder with agoraphobia. Am J Psychiatry. 2013; 170:1345-1355. [PubMed: 23982225]

30. Yang Y, Kircher T, Straube B. The neural correlates of cognitive behavioral therapy: recent progress in the investigation of patients with panic disorder. Behav Res Ther. 2014; 62:88-96. [PubMed: 25124776]

31. Fonzo GA, Ramsawh HJ, Flagan TM, Sullivan SG, Simmons AN, Paulus MP, Stein MB. Cognitive-behavioral therapy for generalized anxiety disorder is associated with attenuation of limbic activation to threat-related facial emotions. J Affect Disord. 2014; 169:76-85. [PubMed: 25171782]

32. Fullana MA, Cardoner N, Alonso P, Subirà M, López-Solà C, Pujol J, Segalàs C, Real E, Bossa M, Zacur E, et al. Brain regions related to fear extinction in obsessive-compulsive disorder and its relation to exposure therapy outcome: a morphometric study. Psychol Med. 2014; 44:845-856. [PubMed: 23773479]

33. Morgiève M, N'Diaye K, Haynes WIA, Granger B, Clair A-H, Pelissolo A, Mallet L. Dynamics of psychotherapy-related cerebral haemodynamic changes in obsessive compulsive disorder using a personalized exposure task in functional magnetic resonance imaging. Psychol Med. 2014; 44:1461-1473. [PubMed: 24001313]

34. Helpman L, Marin M-F, Papini S, Zhu X, Sullivan GM, Schneier F, Neria M, Shvil E, Malaga Aragon MJ, Markowitz JC, et al. Neural changes in extinction recall following prolonged exposure treatment for PTSD: A longitudinal fMRI study. Neuroimage Clin. 2016; 12:715-723. [PubMed: 27761402]

35. Klumpp H, Fitzgerald DA, Angstadt M, Post D, Phan KL. Neural response during attentional control and emotion processing predicts improvement after cognitive behavioral therapy in generalized social anxiety disorder. Psychol Med. 2014; 44:3109-3121. [PubMed: 25066308]

36. Klumpp H, Keutmann MK, Fitzgerald DA, Shankman SA, Phan KL. Resting state amygdalaprefrontal connectivity predicts symptom change after cognitive behavioral therapy in generalized social anxiety disorder. Biol Mood Anxiety Disord. 2014; 4:14. [PubMed: 25540682]

37. Odegaard B, Knight RT, Lau H. Should A Few Null Findings Falsify Prefrontal Theories Of Conscious Perception? Journal of Neuroscience. 2017; 37:9593-9602. * This article reviews the importance of the prefrontal cortex in consciousness. [PubMed: 28978696]

38. Lindquist KA, Barrett LF. A functional architecture of the human brain: emerging insights from the science of emotion. Trends Cogn Sci. 2012; 16:533-540. [PubMed: 23036719]

39. Killgore WDS, Britton JC, Schwab ZJ, Price LM, Weiner MR, Gold AL, Rosso IM, Simon NM, Pollack MH, Rauch SL. Cortico-limbic responses to masked affective faces across ptsd, panic disorder, and specific phobia. Depress Anxiety. 2014; 31:150-159. [PubMed: 23861215]

40. Capitão LP, Underdown SJV, Vile S, Yang E, Harmer CJ, Murphy SE. Anxiety increases breakthrough of threat stimuli in continuous flash suppression. Emotion. 2014; 14:1027-1036. [PubMed: 25286072]

41. Nuske HJ, Vivanti G, Hudry K, Dissanayake C. Pupillometry reveals reduced unconscious emotional reactivity in autism. Biol Psychol. 2014; 101:24-35. [PubMed: 25017502]

42. Vizueta N, Patrick CJ, Jiang Y, Thomas KM, He S. Dispositional fear, negative affectivity, and neuroimaging response to visually suppressed emotional faces. Neuroimage. 2012; 59:761-771. [PubMed: 21771661]

43. McCrory EJ, De Brito SA, Kelly PA, Bird G, Sebastian CL, Mechelli A, Samuel S, Viding E. Amygdala activation in maltreated children during pre-attentive emotional processing. Br J Psychiatry. 2013; 202:269-276. [PubMed: 23470285]

44. Viding E, Sebastian CL, Dadds MR, Lockwood PL, Cecil CAM, De Brito SA, McCrory EJ. Amygdala response to preattentive masked fear in children with conduct problems: the role of callous-unemotional traits. Am J Psychiatry. 2012; 169:1109-1116. [PubMed: 23032389]

45. Jusyte A, Mayer SV, Künzel E, Hautzinger M, Schönenberg M. Unemotional traits predict early processing deficit for fearful expressions in young violent offenders: an investigation using continuous flash suppression. Psychol Med. 2015; 45:285-297. [PubMed: 25066013]

Curr Opin Behav Sci. Author manuscript; available in PMC 2019 December 01. 
46. Clarkin JF, Levy KN, Lenzenweger MF, Kernberg OF. Evaluating three treatments for borderline personality disorder: a multiwave study. Am J Psychiatry. 2007; 164:922-928. [PubMed: 17541052]

47. Kernberg OF, Yeomans FE, Clarkin JF, Levy KN. Transference focused psychotherapy: overview and update. Int J Psychoanal. 2008; 89:601-620. [PubMed: 18558958]

48. Lane RD, Ryan L, Nadel L, Greenberg L. Memory reconsolidation, emotional arousal, and the process of change in psychotherapy: New insights from brain science. Behav Brain Sci. 2015; 38:e1. [PubMed: 24827452]

49. Golden WL. Cognitive hypnotherapy for anxiety disorders. Am J Clin Hypn. 2012; 54:263-274. [PubMed: 22655330]

50. Lee CW, Cuijpers P. A meta-analysis of the contribution of eye movements in processing emotional memories. J Behav Ther Exp Psychiatry. 2013; 44:231-239. [PubMed: 23266601]

51. Perera T, George MS, Grammer G, Janicak PG, Pascual-Leone A, Wirecki TS. The Clinical TMS Society Consensus Review and Treatment Recommendations for TMS Therapy for Major Depressive Disorder. Brain Stimul. 2016; 9:336-346. [PubMed: 27090022]

52. Berlim MT, Van den Eynde F, Daskalakis ZJ. Clinical utility of transcranial direct current stimulation (tDCS) for treating major depression: a systematic review and meta-analysis of randomized, double-blind and sham-controlled trials. J Psychiatr Res. 2013; 47:1-7. [PubMed: 23084964]

53. Ramot M, Grossman S, Friedman D, Malach R. Covert neurofeedback without awareness shapes cortical network spontaneous connectivity. Proc Natl Acad Sci U S A. 2016; 113:E2413-20. * This study shows that functional brain connectivity can be changed unconsciously in a doubleblind placebo controlled Neural-Reinforcement experiment. [PubMed: 27071084]

54. Ramot M, Kimmich S, Gonzalez-Castillo J, Roopchansingh V, Popal H, White E, Gotts SJ, Martin A. Direct modulation of aberrant brain network connectivity through real-time NeuroFeedback. Elife. 2017; $6 * *$ This study shows that abnormal brain connectivity can be changed in individuals presenting autism spectrum disorder using Neural-Reinforcement.

55. Fovet T, Micoulaud-Franchi J-A, Vialatte F-B, Lotte F, Daudet C, Batail J-M, Mattout J, Wood G, Jardri R, Enriquez-Geppert S, et al. On assessing neurofeedback effects: should double-blind replace neurophysiological mechanisms? Brain. 2017; 140:e63. [PubMed: 28969378]

56. Popper K. The Logic of Scientific Discovery. London, Routledge: 2002.

57. Price DD, Finniss DG, Benedetti F. A comprehensive review of the placebo effect: recent advances and current thought. Annu Rev Psychol. 2008; 59:565-590. [PubMed: 17550344]

58. Watanabe T, Sasaki Y, Shibata K, Kawato M. Advances in fMRI Real-Time Neurofeedback. Trends Cogn Sci. 2017; 21:997-1010. ** A recent review of new Neural-Reinforcement methods, including Decoded Neural-Reinforcement and functional connectivity-based NeuralReinforcement. [PubMed: 29031663]

59. Moutard C, Dehaene S, Malach R. Spontaneous Fluctuations and Non-linear Ignitions: Two Dynamic Faces of Cortical Recurrent Loops. Neuron. 2015; 88:194-206. [PubMed: 26447581]

60. Loerinc AG, Meuret AE, Twohig MP, Rosenfield D, Bluett EJ, Craske MG. Response rates for CBT for anxiety disorders: Need for standardized criteria. Clin Psychol Rev. 2015; 42:72-82. [PubMed: 26319194]

61. Sloan T, Telch MJ. The effects of safety-seeking behavior and guided threat reappraisal on fear reduction during exposure: an experimental investigation. Behav Res Ther. 2002; 40:235-251. [PubMed: 11863235]

62. Koizumi A, Amano K, Cortese A, Shibata K, Yoshida W, Seymour B, Kawato M, Lau H. Fear reduction without fear through reinforcement of neural activity that bypasses conscious exposure. Nat Hum Behav. 2016; 1 ** This study shows that conditioned physiological fear responses can be decreased unconsciously using Neural-Reinforcement.

63. Taschereau-Dumouchel V, Cortese A, Chiba T, Knotts JD, Kawato M, Lau H. Towards an unconscious neural reinforcement intervention for common fears. Proc Natl Acad Sci U S A. 2018; 115:3470-3475. ** This study shows that the physiological fear responses associated with naturally occuring animal fears can be decreased using Neural-Reinforcement. [PubMed: 29511106] 
64. Haxby JV, Connolly AC, Guntupalli JS. Decoding neural representational spaces using multivariate pattern analysis. Annu Rev Neurosci. 2014; 37:435-456. [PubMed: 25002277]

65. He J, Sun H-Q, Li S-X, Zhang W-H, Shi J, Ai S-Z, Li Y, Li X-J, Tang X-D, Lu L. Effect of conditioned stimulus exposure during slow wave sleep on fear memory extinction in humans. Sleep. 2015; 38:423-431. [PubMed: 25348121]

66. Hauner KK, Howard JD, Zelano C, Gottfried JA. Stimulus-specific enhancement of fear extinction during slow-wave sleep. Nat Neurosci. 2013; 16:1553-1555. [PubMed: 24056700]

67. Arzi A, Holtzman Y, Samnon P, Eshel N, Harel E, Sobel N. Olfactory aversive conditioning during sleep reduces cigarette-smoking behavior. J Neurosci. 2014; 34:15382-15393. [PubMed: 25392505]

68. Gagliano M, Vyazovskiy VV, Borbély AA, Grimonprez M, Depczynski M. Learning by Association in Plants. Sci Rep. 2016; 6:38427. [PubMed: 27910933]

69. Ader R. Conditioned immunomodulation: research needs and directions. Brain Behav Immun. 2003; 17(Suppl 1):S51-7. [PubMed: 12615187]

70. Jensen K, Kirsch I, Odmalm S, Kaptchuk TJ, Ingvar M. Classical conditioning of analgesic and hyperalgesic pain responses without conscious awareness. Proc Natl Acad Sci U S A. 2015; 112:7863-7867. [PubMed: 25979940]

71. Benedetti F, Mayberg HS, Wager TD, Stohler CS, Zubieta J-K. Neurobiological mechanisms of the placebo effect. J Neurosci. 2005; 25:10390-10402. [PubMed: 16280578]

72. Matzinger P. Tolerance, Danger and the Extended Family. Annu Rev Immunol. 1994; 12:9911045. [PubMed: 8011301]

73. Askew C, Field AP. The vicarious learning pathway to fear 40 years on. Clin Psychol Rev. 2008; 28:1249-1265. [PubMed: 18614263]

74. Bach J-F. The effect of infections on susceptibility to autoimmune and allergic diseases. N Engl J Med. 2002; 347:911-920. [PubMed: 12239261]

75. Strachan DP, Aït-Khaled N, Foliaki S, Mallol J, Odhiambo J, Pearce N, Williams HC. ISAAC Phase Three Study Group. Siblings, asthma, rhinoconjunctivitis and eczema: a worldwide perspective from the International Study of Asthma and Allergies in Childhood. Clin Exp Allergy. 2015; 45:126-136. [PubMed: 24912652]

76. Cheng G, Smith AM, Levin L, Epstein T, Ryan PH, LeMasters GK, Khurana Hershey GK, Reponen T, Villareal M, Lockey J, et al. Duration of day care attendance during infancy predicts asthma at the age of seven: the Cincinnati Childhood Allergy and Air Pollution Study. Clin Exp Allergy. 2014; 44:1274-1281. [PubMed: 25179746]

77. Riedler J, Braun-Fahrländer C, Eder W, Schreuer M, Waser M, Maisch S, Carr D, Schierl R, Nowak D, von Mutius E, et al. Exposure to farming in early life and development of asthma and allergy: a cross-sectional survey. Lancet. 2001; 358:1129-1133. [PubMed: 11597666]

78. Strachan DP. Hay fever, hygiene, and household size. BMJ. 1989; 299:1259-1260. [PubMed: 2513902]

79. Lambrecht BN, Hammad H. The immunology of the allergy epidemic and the hygiene hypothesis. Nat Immunol. 2017; 18:1076-1083. [PubMed: 28926539]

80. Olsson A, Phelps EA. Social learning of fear. Nat Neurosci. 2007; 10:1095-1102. [PubMed: 17726475]

81. Sterley T-L, Baimoukhametova D, Füzesi T, Zurek AA, Daviu N, Rasiah NP, Rosenegger D, Bains JS. Social transmission and buffering of synaptic changes after stress. Nat Neurosci. 2018; doi: 10.1038/s41593-017-0044-6 
Highlights

- Unconscious physiological survival circuits are involved in various mental illnesses.

- Unconsciously targeting the survival/defensive circuit might benefit anxiety disorders.

- Theoretically, other survival-related physiological circuits could also be targeted. 


\section{Box 1}

\section{Do autoimmune diseases spread through the social network?}

Incidence rates of autoimmune diseases such as Type 1 diabetes and multiple sclerosis have been increasing with substantial cross-country differences [74]. But the epidemiological findings are equivocal: the geographical and other epidemiological patterns of autoimmune diseases [75-77] are also consistent with a mechanism of unconscious spreading through social networks, as much as they could lend support to the popular hygiene hypothesis [78] or its updated versions that focus more on microbiome diversity [79]. The exact mechanisms remain unclear. One way to make sense of these results may be to conceptualize autoimmune reactions as something akin to fear, whereby the purpose of the process is to pre-emptively respond to an external treat; occasionally such over-reactions lead to problems by blocking the action of other effective mechanisms. In humans as well as other animals, there is direct experimental evidence that some fear-related processes can be transmitted socially through vicarious learning [80,81]. 
A)

\section{Stimulus}
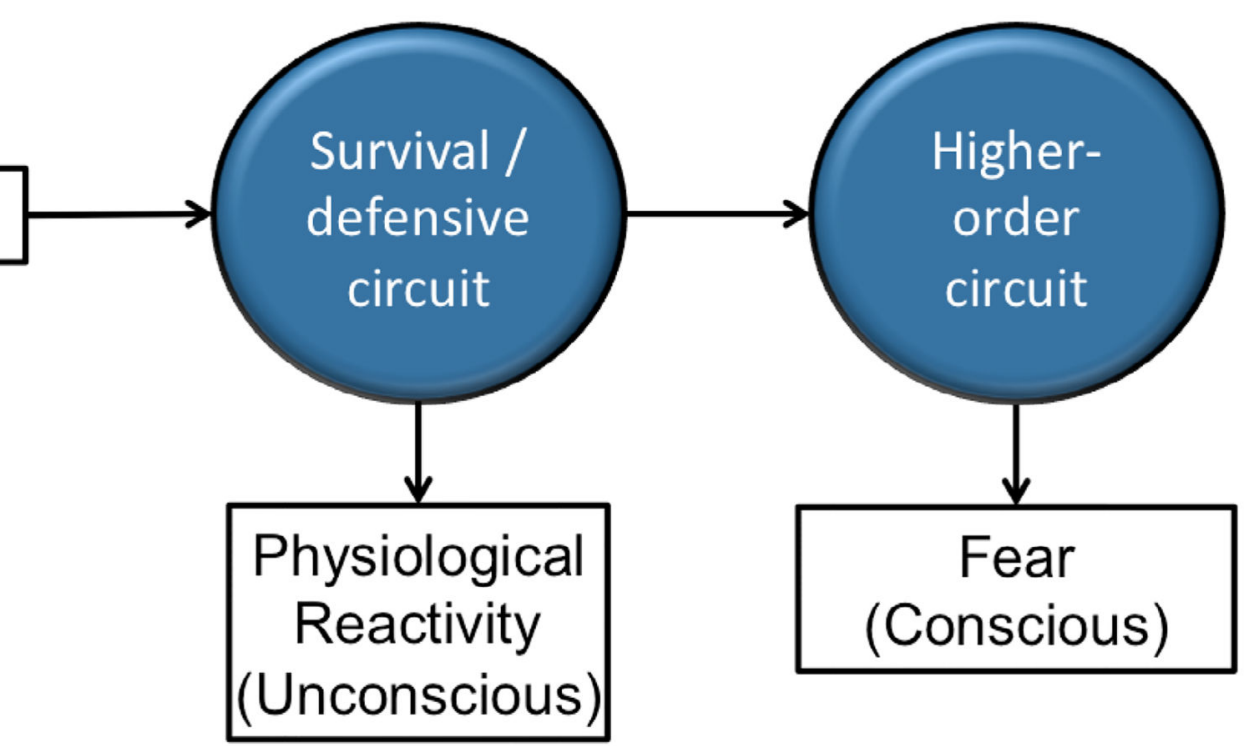

B)

\section{Stimulus}

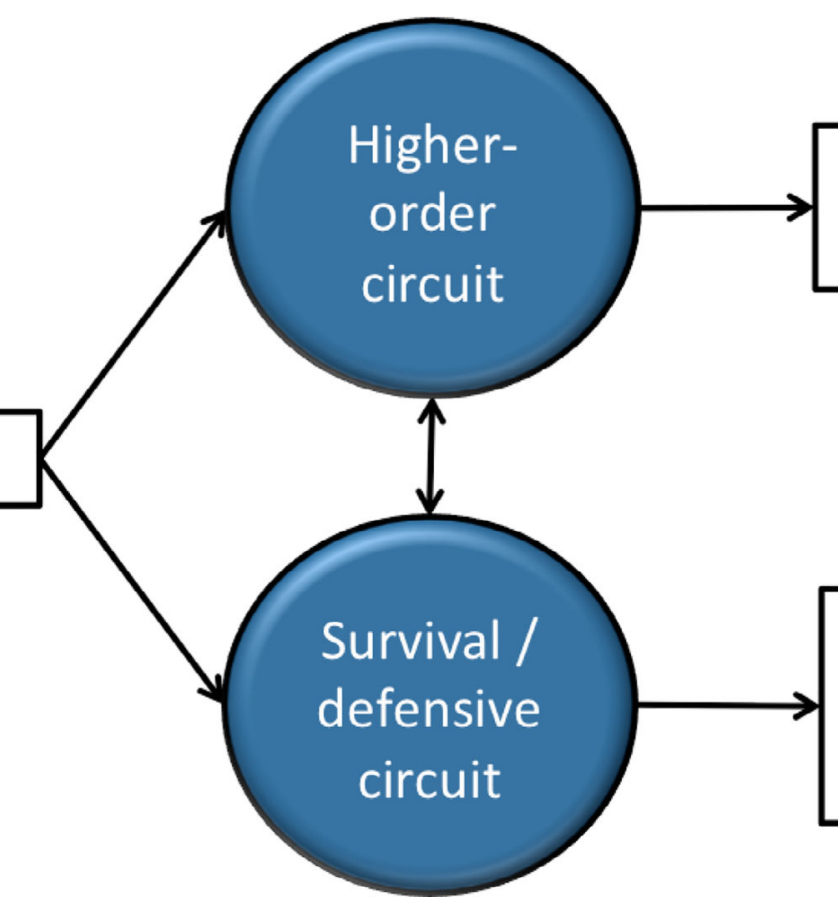

Physiological Reactivity (Unconscious)

Figure 1. Interactions between the survival/defensive circuit and the higher-order circuit (A) According to some views (e.g. the higher-order view of consciousness [4]), the physiological mechanism relevant for dealing with immediate threat is considered to be the unconscious bases which ultimately lead to the higher-order process determining the conscious experience of fear. (B) An alternative is to conceptualize the two processes as operating in parallel. But even under such views, few would consider that the two processes do not interact at all. 
A) Online decoding Target decoder

B)
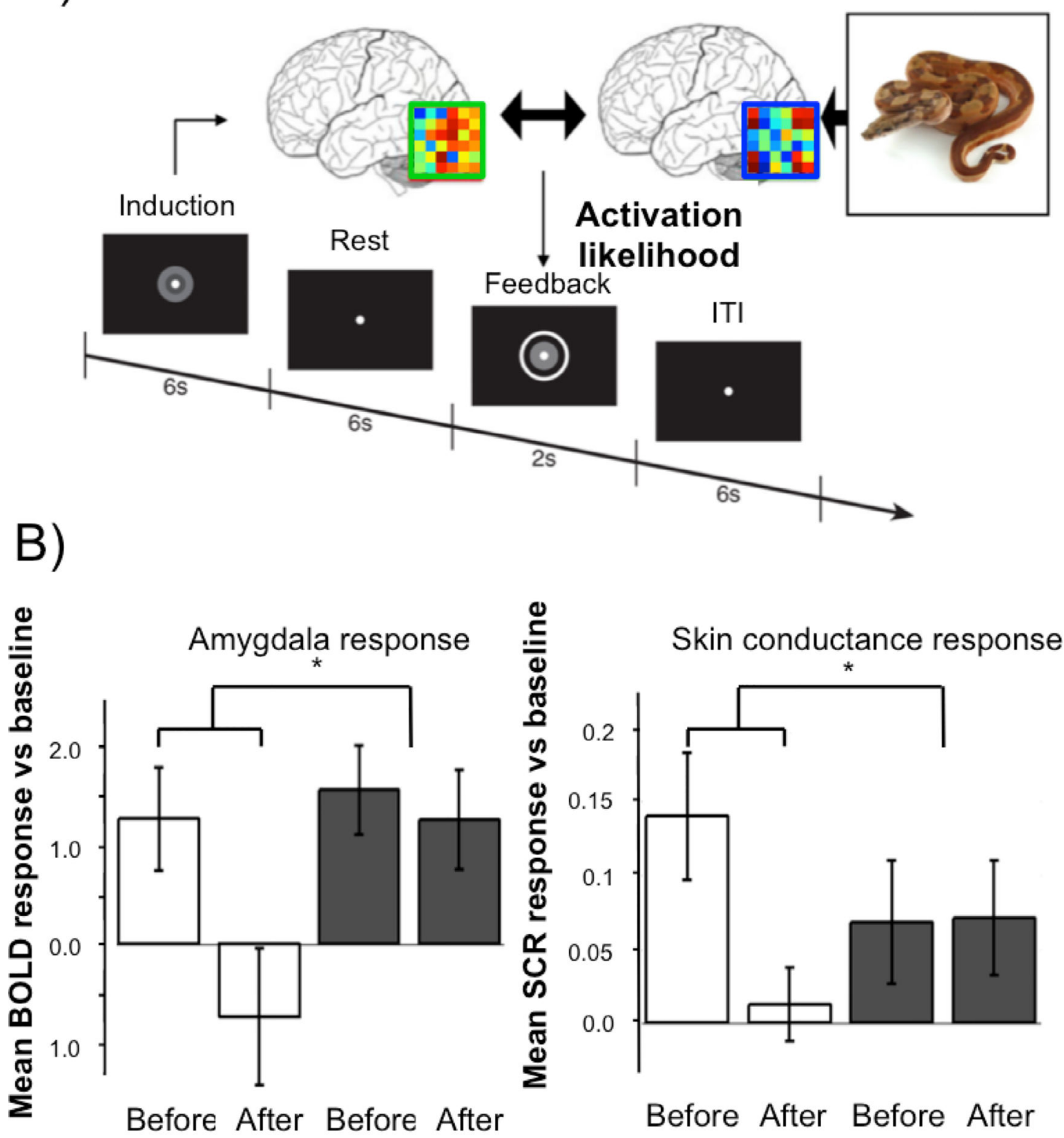

Target condition

$\square$ Control condition

Figure 2. An unconscious Neural-Reinforcement intervention targeting naturally occurring animal fears

(A) Procedure in one trial of Decoded Neural-Reinforcement. Online decoding was used to reinforce occurrences of the multivoxel representation of a feared animal (e.g., a snake). The feedback was proportional to the likelihood of the feared animal being represented. (B) Using this method, we demonstrated in a double-blind placebo-controlled experiment that Neural-Reinforcement can lead to reliable reductions in physiological fear responses measured by amygdala hemodynamic activity (left panel) and skin conductance response (right panel) [63]. 


\section{Table 1}

Some recent studies on the unconscious activation of the survival/defensive circuit in mental illnesses

\begin{tabular}{|c|c|c|c|c|}
\hline Population & Methods & Stimuli & Outcome & References \\
\hline $\begin{array}{l}\text { Specific phobia, PTSD, and } \\
\text { panic disorder }\end{array}$ & backward masking & Fearful faces & $\begin{array}{l}\nearrow \text { activity in the left amygdala and } \searrow \text { activity } \\
\text { in the vmPFC in patients. }\end{array}$ & {$[39]$} \\
\hline Spider phobia & Backward masking & Spiders & $\begin{array}{c}\text { Tamygdala, hippocampus, para-hippocampus, } \\
\text { superior temporal gyrus, and dlPFC in } \\
\text { patients. }\end{array}$ & {$[22]$} \\
\hline Trait anxiety & CFS & Threatening faces & Faster break through with higher trait anxiety & {$[40]$} \\
\hline Autism & Backward masking & Fearful faces & $\searrow$ pupillary response in patients & {$[41]$} \\
\hline Negative affectivity & CFS & Fearful faces & $\begin{array}{l}7 \text { response in right amygdala and superior } \\
\text { temporal sulcus with higher negative } \\
\text { affectivity }\end{array}$ & {$[42]$} \\
\hline Maltreated children & $\begin{array}{l}\text { Masked dot probe } \\
\text { paradigm }\end{array}$ & Emotional faces & $\begin{array}{l}7 \text { response in the right amygdala for } \\
\text { emotional faces in maltreated children. }\end{array}$ & {$[43]$} \\
\hline $\begin{array}{l}\text { Callous-unemotional traits in } \\
\text { conduct disorders }\end{array}$ & Backward masking & Fearful faces & $\begin{array}{l}\nearrow \text { response in the right amygdala with low } \\
\text { callous-unemotional traits. }\end{array}$ & {$[44]$} \\
\hline $\begin{array}{l}\text { Unemotional traits in young } \\
\text { violent offenders }\end{array}$ & CFS & Emotional faces & $\begin{array}{c}\text { Faster break through with lower unemotional } \\
\text { traits. }\end{array}$ & {$[45]$} \\
\hline
\end{tabular}

CFS: Continuous flash suppression. 